\title{
Colorectal endoscopic submucosal dissection can be efficiently performed by a trainee with use of a simple traction device and expert supervision
}

\section{다)(1) $\odot$}

\author{
Authors \\ Daisuke Ide $^{1,2}$, Shoichi Saito ${ }^{1}$, Tomohiko Richard Ohya ${ }^{3}$, Yuske Nishikawa ${ }^{1}$, Yoshimasa Horie ${ }^{1}$, Chihiro Yasue ${ }^{1}$, Akiko \\ Chino $^{1}$, Masahiro Igarashi ${ }^{1}$, Masayuki Saruta², Junko Fujisaki ${ }^{4}$
}

Institutions

1 Department of Lower Gastrointestinal Medicine, The Cancer Institute Hospital of Japanese Foundation for Cancer Research, Tokyo, Japan

2 Department of Internal Medicine, Division of Gastroenterology and Hepatology, The Jikei University School of Medicine, Tokyo, Japan

3 Department of Endoscopy, The Jikei University School of Medicine, Tokyo, Japan

4 Department of Upper Gastrointestinal Medicine, The Cancer Institute Hospital of Japanese Foundation for Cancer Research, Tokyo, Japan

submitted 18.8.2018

accepted after revision 26.2.2019

\author{
Bibliography \\ DOI https://doi.org/10.1055/a-0901-7113 | \\ Endoscopy International Open 2019; 07: E824-E832 \\ (c) Georg Thieme Verlag KG Stuttgart · New York \\ eISSN 2196-9736
}

Corresponding author

Daisuke Ide, MD, PhD, Department of Lower

Gastrointestinal Medicine, The Cancer Institute Hospital of Japanese Foundation for Cancer Research, 3-8-31, Ariake, Koto, Tokyo 135-8550, Japan

Fax: +81-3-3520-0141

dei0405@gmail.com

\section{ABSTRACT}

Background and study aims Colorectal endoscopic submucosal dissection (ESD) is technically challenging owing to submucosal fibrosis and difficult endoscope manipulation. Therefore, various traction methods have been reported. We often use a simple looped nylon thread attached to a clip to assist with dissection. We assessed the feasibility of mentor-guided colorectal ESD using this traction device (TD).

Patients and methods From December 2017 to March 2018 , we retrospectively reviewed outcomes of 101 colorectal ESDs performed by two groups of endoscopists (A, 5 endoscopists with colorectal ESD experience of $<50$ cases; B, 5 endoscopists with experience of $>300$ cases). Group A was further divided into two subgroups that performed ESD with or without TD.

Results No significant difference was observed in ESD completion rates (86.1\% [62/72] vs. 96.6\% [28/29]; odds ratio [OR], 0.22; $95 \%$ confidence interval [Cl], $0.005-1.71$; $P=0.17)$ or procedure times $(52.0 \mathrm{~min}$ vs. $40.0 \mathrm{~min}$; $P=$ 0.27 ) and adverse event rates between groups $A$ and $B$. The rate of TD use was significantly higher in group $A$ than in group B (44.4\% [32/72] vs. $20.7 \%$ [6/29]; OR, 3.03; Cl, $1.04-10.23 ; P=0.03)$. The completion rate was not different between the two subgroups of group A (with vs. without TD) $(81.2 \%$ [26/32] vs. $90.0 \%$ [36/40]; OR, 0.49; Cl, $0.09-2.29 ; P=0.32)$; however, the proportion of fibrosis cases was significantly higher in the TD-use group (46.8\% [15/32] vs. 22.5\% [9/40]; OR, 2.99; Cl, 0.98-9.59; $P=$ $0.03)$.

Conclusion Mentor-guided colorectal ESD using TD was performed efficiently, safely, and in a manner comparable to that of experts.

\section{Introduction}

Technological breakthroughs have led to novel endoscopic techniques for diagnosing and treating gastrointestinal diseases. Although endoscopic mucosal resection for colorectal tumors is widely used as a minimally invasive therapy, the size of lesions that can be collectively resected is, on average, $20 \mathrm{~mm}$ due to the limits of the snare diameter. In Japan, endoscopic submucosal dissection (ESD) was developed as a method that enables reliable en bloc resection for early gastric cancer so that accurate histopathological evaluations can be achieved $[1,2]$. 
With this method, an array of novel needle knives can be used as an electric scalpel to surgically remove the submucosal layer just beneath the diseased mucosa [2-9]. However, repetitive and meticulous needle knife electrosurgical dissections of the submucosa during ESD remain physically and mentally demanding for the operator and involve high risk of perforation. Compared with the stomach, especially in the colorectum, the muscularis propria is thin and operability of the endoscope is unstable. When perforation occurs, severe peritonitis is caused by bacterial contamination of the peritoneal cavity [10]. Presence of fibrosis in the submucosal layer is considered one of the major factors that increase the difficulty of colorectal ESD. Various techniques such as the traction method have been developed to efficiently and safely perform ESD in gastrointestinal tumors when difficulties are encountered [11-18]. Among these techniques, ESD using the $\mathrm{S}-\mathrm{O}$ clip has been reported to decrease procedure time without compromising on safety [19, 20]. We recently introduced a new technique called submucosal pocket creation, which uses a traction device (TD) [21]. Thus, it is now possible to perform colorectal ESD relatively safely and reliably with development and improvement of these ESD-related treatment instruments.

The difficulty of colorectal ESD is greatly affected by peristaltic bowel movements. Anatomically, the lumen is narrow, with large bends and folds compared to that of the stomach. When novice endoscopists attempt colorectal ESD without any guidance, it is highly probable that they will encounter several obstacles related to stabilization of the working space and difficulties maneuvering the endoscope tip. Therefore, excellent colonoscopy handling skills are a necessity, and mentor guidance throughout the procedure is helpful $[22,23]$. The long learning curve involved in mastering colorectal ESD is a major factor preventing use of this method worldwide [24].

Recently, studies utilizing animal models as a useful training method for colorectal ESD have been reported. However, few studies have evaluated use of the TD technique for human colorectal ESD performed by trainee endoscopists. Furthermore, no study has compared treatment outcomes based on use of the simple loop nylon thread TD during colorectal ESD performed by trainees and experts. We retrospectively investigated whether colorectal ESD using a TD could enable novice operators to become proficient at performing colorectal ESD; this study aimed to evaluate the usefulness of TD in colorectal ESD performed by trainee endoscopists under mentor supervision.

\section{Patients and methods}

We retrospectively reviewed medical records and endoscopic report data from The Cancer Institute Hospital of the Japanese Foundation for Cancer Research from December 2017 to May 2018 and found that 104 patients with 105 colorectal lesions underwent ESD. Four patients with four lesions that were not neoplastic were excluded from this study.

To evaluate the therapeutic outcomes of trainee endoscopists, we investigated the outcomes of 101 colorectal ESDs performed by two groups of endoscopists (group A and B). Group A comprised five less-experienced endoscopists (trai- nees: less than 50 cases of colorectal ESD), and group B comprised five more experienced endoscopists (experts: more than 300 cases of colorectal ESD). All trainees fulfilled the following criteria: 1 ) experience with more than 500 colonoscopy examinations; 2) accurate diagnostic capability using magnifying endoscopy; 3 ) proficiency with the endoscopic mucosal resection technique; and 4) 2 to 3 months of training involving observing and assisting ESD.

The lesions included in this study were colorectal laterally spreading tumors, residual or recurrent lesions, protruding tumors $\geq 20 \mathrm{~mm}$, and submucosal tumors (SMTs) suspected to be neuroendocrine tumors $\geq 5 \mathrm{~mm}$ in diameter. Regarding epithelial tumors, chromoendoscopy and magnification endoscopy were performed before ESD to confirm that there was no deep invasion into the submucosal layer. Endoscopic ultrasound was performed for SMTs to confirm absence of infiltration into the muscular layer. Trainees performed colorectal ESDs under expert supervision. Guidance regarding incisions, dissection, and hemostasis was provided using verbal instructions. When procedure time was predicted to be prolonged or when technically difficult factors such as severe submucosal fibrosis were encountered, a nylon loop TD was used at the discretion of the operator and the supervisor.

Rates of accomplishing ESD, rates of TD use, procedure times, en bloc and $\mathrm{R} 0$ resection rates, and rates of adverse events (AEs), including perforation and postoperative bleeding, of the trainee group (group A) and the expert group (group B) were included in this analysis. We also divided the trainee group into subgroups based on whether the TD was used during colorectal ESD. The same aforementioned factors were compared during the subgroup analysis of the trainee group (group A) with or without use of TD.

Procedure time was defined as time from initial local injection in the submucosal layer to complete resection of the lesion. En bloc resection was defined as removal of the whole lesion. $\mathrm{R} 0$ resection was defined as removal of the whole lesion with a negative excision margin. AEs included perforation and postoperative bleeding. Intraoperative and delayed perforations were collectively termed as perforation. Postoperative bleeding was defined as bloody stools that occurred within 2 weeks after ESD and required endoscopic hemostasis.

This study complied with standards of the Declaration of Helsinki and the current ethical guidelines, and it was approved by the institutional ethics board of The Cancer Institute Hospital of the Japanese Foundation for Cancer Research. Written informed consent for participation in this study was not obtained from the patients because this study did not report a clinical trial and the data were retrospective in nature and analyzed anonymously.

\section{Design of the traction device}

We modified the commercially available S-O clip. The TD used in this study was a loop made of nylon thread attached to an endoscopic clip. The diameter of the nylon loop was approximately $15 \mathrm{~mm}$ ( $\triangleright$ Fig. 1). Unlike the S-O clip, this TD cannot be stretched because it does not have a spring; however, it can easily control the tension applied to the lesion by adjusting the 

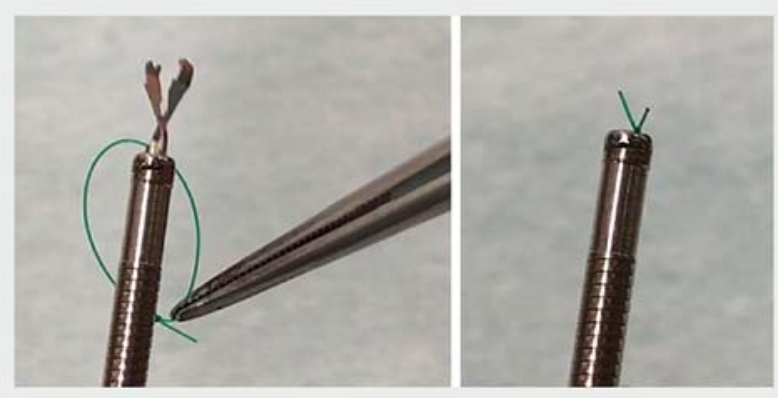

- Fig. 1 Nylon loop traction device used in this study. The traction device consisted of a nylon loop with a diameter of approximately $15 \mathrm{~mm}$ attached to the base of the endoscopic clip.

amount of air in the lumen. In addition, similar to the S-O clip, this TD can pass through the channel of the forceps of the endoscope; therefore, removal and reinsertion of the endoscope are not necessary. Furthermore, because this TD is an endoscope-independent treatment tool, it can be used regardless of lesion location.

\section{Endoscopic procedure}

Midazolam and pethidine hydrochloride were used as a sedative and an analgesic, respectively, for all patients. All patients were administered antispasmodic agents such as butyl scopolamine bromide or glucagon. We used a video endoscope equipped with a secondary water supply channel (GIF-Q260) or PCFQ260]; Olympus, Tokyo, Japan) fitted with a disposable tip attachment (D-201-11804; Olympus, Tokyo, Japan). In this study, $0.4 \%$ sodium hyaluronate solution (MucoUp; Biochemistry, Tokyo, Japan) containing a small amount of indigo carmine and epinephrine hydrochloride was used as the submucosal injection.

We performed the mucosal and submucosal incisions using a dual knife or dual knife J (KD-650 Q or KD 655 Q; Olympus, Tokyo, Japan). When arterial bleeding was observed, hemostasis treatment was performed using hemostatic forceps (FD$411 \mathrm{QR}$; Olympus) as appropriate. The VIO $300 \mathrm{D}$ (ERBE Elektromedizin $\mathrm{GmbH}$, Tubingen, Germany) was used as the high-frequency generator device for our procedures.

Mucosal incision and most of the dissection were performed in Endo-Cut I mode (effect, 2; duration, 2; interval, 2). For submucosa with much fatty tissue and many vessels, dissection was performed using the SWIFT coagulation mode (effect 3; $45 \mathrm{~W})$. Carbon dioxide $\left(\mathrm{CO}_{2}\right)$ was used for insufflation in all patients.

Regarding the conventional ESD procedure, after sufficient submucosal injection to the lesion site, mucosal incision and submucosal dissection on the proximal side of the lesion were performed with the endoscope in the retroflex position when possible. Following proximal edge excision, mucosal incision and submucosal dissection of the distal side of the lesion were performed. An optional submucosal injection was used when

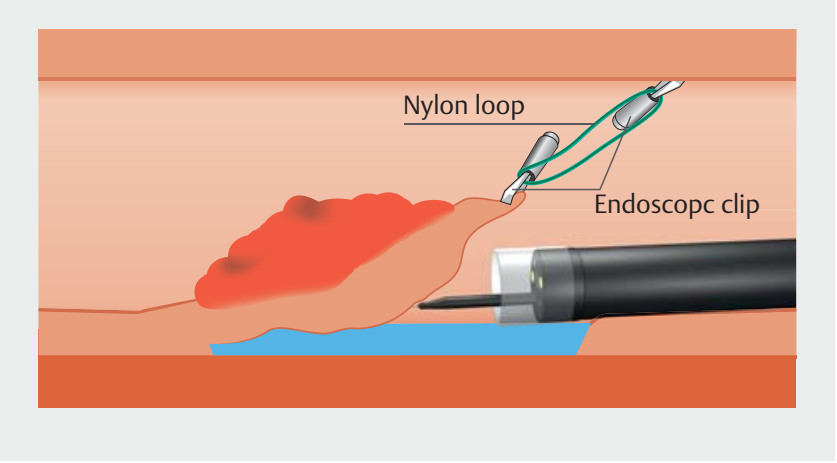

Fig. 2 Schema of the nylon loop traction device.

necessary, and submucosal dissection was repeated to complete the procedure.

During ESD using the TD, initial mucosal incision and partial dissection were performed in the same manner as that during conventional ESD. After full or semi-circumferential cutting, the nylon loop TD was applied to the distal edge of the partially dissected lesion. The nylon loop thread was hooked with a clip and attached to the colorectal wall opposite to the lesion ( Fig. 2, \ Fig.3). As a result, moderate tension was applied to the submucosal layer of the lesion, thus allowing easier identification of the dissection plane.

\section{Statistical analysis}

Because there is a possibility that patient characteristics between Group A and Group B are different, the following patient characteristics were analyzed: age, gender, location, morphology, lesion size, specimen size, pathological findings, residual or recurrent lesion, and fibrosis. Outcomes of interest in this study were rates of accomplishing ESD, rates of TD use, procedure times, rates of en bloc and RO resection, and rates of AEs, including perforation and postoperative bleeding, between Group A and Group B.

Comparisons between groups were performed using the Mann-Whitney U-test, and the Student's t-test was used for continuous variables. Categorical variables were compared using the chi-squared and Fisher's exact tests. Differences with a $P$ value $<0.05$ were considered statistically significant. Statistical analysis was performed using R version 3.4.2 ( $R$ Foundation, Vienna, Austria).

\section{Results}

The TD was used for 38 lesions. In all cases, ESD using TD was successful. TD use was not discontinued in any case during ESD. Moreover, the TD did not interfere with the ESD procedure.

Baseline characteristics of patients and lesions are shown in - Table 1. In all, 72 and 29 lesions were removed by trainee endoscopists (group A) and expert endoscopists (group B), respectively. There were no significant differences in baseline characteristics such as age, gender, tumor location, morphology, lesion size, specimen size, pathological findings, number of 


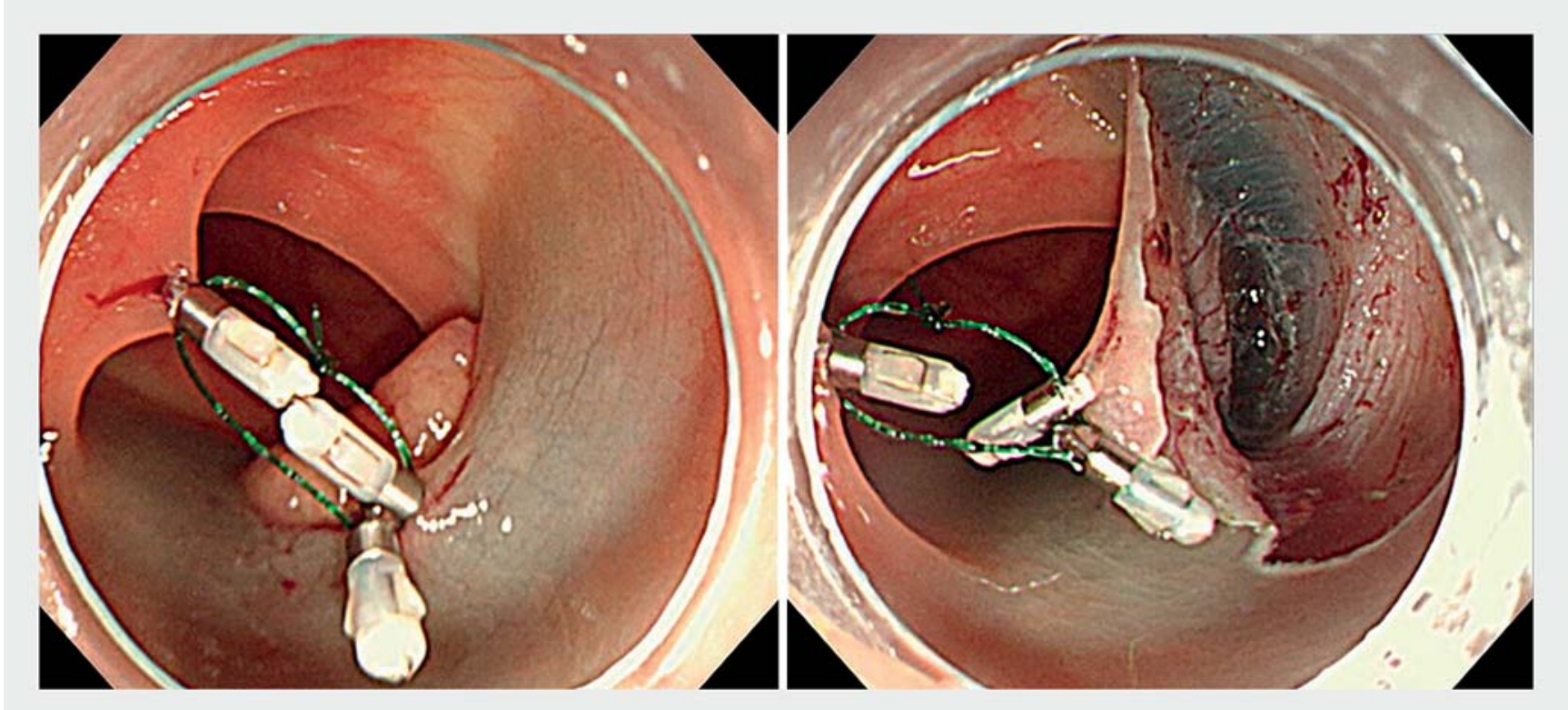

- Fig. 3 Colorectal endoscopic submucosal dissection using the traction device. The traction device was attached to the normal mucosa from the distal side of the tumor after full or semi-circumferential cutting. The nylon loop thread was hooked with a clip and attached to the colorectal wall opposite to the lesion, and dissection was continued with sufficient countertraction.

residual or recurrent lesions, and fibrosis between the two groups.

Treatment outcomes of the two groups are shown in $\triangleright$ Table 2. No significant difference was observed in ESD completion rates (86.1\% [62/72] vs. 96.6\% [28/29]; odds ratio [OR], 0.22; $95 \%$ confidence interval $[\mathrm{Cl}], 0.005-1.71 ; P=0.17$ ) or procedure times ( $51.5 \mathrm{~min}$ vs. $40.0 \mathrm{~min}, P=0.42$ ) between the two groups. In group A, 10 lesions for which ESD could not be completed independently by the trainee were removed with the help of an expert who completed the ESD procedure. ESD could not be completed in one patient in group B due to the muscleretracting sign caused by the peristaltic pulling force on the muscle layer just under the lesion toward the tumor. For this patient, ESD was discontinued and surgery was performed later. The rate of TD use was significantly higher in group $A$ than in group B (44.4\% [32/72] vs. 20.7\% [6/29]; OR, 3.03; $95 \% \mathrm{Cl}$, $1.04-10.23 ; P=0.03)$. Between the two groups, rates of en bloc, R0, curative resections, and AEs were comparable. Although there were no perforations in group $B$, two minor perforations occurred during the procedure in group $\mathrm{A}(2.8 \%$ [2/72] vs. $0 \%$ [0/29]; $P=1.00)$. Neither perforation required surgery; instead, wound closure using the endoscopic clip was performed and antibiotics were administered. No deaths were associated with the treatment.

\section{Subgroup analyses of trainee endoscopists}

Of the 72 lesions treated with ESD by trainees, 32 lesions were resected with the TD and 40 lesions were resected without the TD. Baseline characteristics of patients and lesions are shown in - Table 3. There were no significant differences in baseline characteristics concerning age, gender, morphology, lesion size, specimen size, pathological findings, and number of resi- dual or recurrent lesions between the two groups. In the TDuse group, lesions occupying the rectum were significantly smaller than those of the TD non-use group (12.5\% [4/32] vs $35 \%$ [14/40]; OR, 0.27; CI, 0.06-1.01; $P=0.03)$. The TD-use group encountered significantly more lesions with fibrosis than the TD non-use group (46.8\% [15/32] vs. $22.5 \%$ [9/40]; OR, 2.99; $\mathrm{Cl}, 0.98-9.59 ; P=0.03)$. Treatment outcomes of the two groups are shown in $>$ Table 4 . No significant difference was observed in ESD completion rates (81.2\% [26/32] vs. $90.0 \%$ [36/40]; OR, 0.49; Cl, 0.09-2.29; $P=0.32$ ) between the two groups. Procedure time was significantly longer in the TDuse group than in the TD non-use group (69.0 min vs. 42.0 min; $P<0.01)$. Between the two groups, rates of en bloc, R0, curative resection, and $\mathrm{AEs}$ were comparable. The experiences of trainees with ESD are shown in $>$ Table 5.

\section{Discussion}

This is one of few reports that show the usefulness of TD for human colorectal ESD performed by trainee endoscopists [25]. In addition, to our knowledge, this study was the first to directly compare treatment outcomes based on use of a TD by trainee and expert endoscopists.

There were no significant differences in ESD completion rates and procedure times of the trainee and expert groups in the current study. Furthermore, high rates of en bloc and R0 resections and low rates of AEs were achieved by the trainee group. Interestingly, the rate of TD use was significantly higher in the trainee group than in the expert group. There were many confounding factors that influenced outcomes of this study, but we believe that this study demonstrated the importance 
- Table 1 Baseline characteristics of the 101 patients treated with ESD.

\begin{tabular}{|c|c|c|c|c|}
\hline & Trainee $(n=72)$ & Expert $(n=29)$ & $95 \% \mathrm{Cl}$ & $P$ value \\
\hline Age, mean (SD), years & $66.2(10.5)$ & $65.0(9.5)$ & $-5.57-3.34$ & $0.62^{1}$ \\
\hline Gender, male: female, n [\%] & 33 [46]: $39[54]$ & 12 [41]: 17 [59] & $0.46-3.18$ & $0.68^{2}$ \\
\hline Location, n [\%] & & & $0.59-9.28$ & $0.22^{2}$ \\
\hline - Rectum & $18[25]$ & $4[14]$ & & \\
\hline - Colon & $54[75]$ & $25[86]$ & & \\
\hline Morphology, n [\%] & & & & $0.06^{3}$ \\
\hline - LST-G & $30[42]$ & $16[55]$ & & \\
\hline - LST-NG & $33[46]$ & $8[28]$ & & \\
\hline - Protruded type & $5[7]$ & $3[10]$ & & \\
\hline - SMT & $4[6]$ & $0[0]$ & & \\
\hline - Other (scar) & $0[0]$ & $2[7]$ & & \\
\hline Lesion size, median [interquartile range], mm & $21.5[18.0-28.5]$ & $25.0[20.0-35.0]$ & & $0.06^{4}$ \\
\hline Specimen size, median [interquartile range], mm & $34.5[28.0-40.0]$ & $35.0[30.0-41.3]$ & & $0.51^{4}$ \\
\hline Pathological findings, n [\%] & & & & $0.41^{3}$ \\
\hline - Adenoma & 35 [49] & $13[45]$ & & \\
\hline - Intramucosal carcinoma & $25[35]$ & $9[31]$ & & \\
\hline - Slightly invasive $(<1000 \mu \mathrm{m})$ & $2[3]$ & $2[7]$ & & \\
\hline - Deeply invasive ( $\geq 1000 \mu \mathrm{m})$ & $6[8]$ & $5[17]$ & & \\
\hline - Neuroendocrine tumor & $4[6]$ & $0[0]$ & & \\
\hline Residual or recurrent lesion & $5[7]$ & $3[10]$ & $0.12-4.48$ & $0.69^{3}$ \\
\hline Fibrosis, n [\%] & $24[33]$ & $10[35]$ & $0.35-2.67$ & $0.91^{2}$ \\
\hline $\begin{array}{l}\text { ESD, endoscopic submucosal dissection; Cl, confidence } \\
\text { type; SMT, submucosal tumor. } \\
{ }^{1} \text { Student's } t \text {-test } \\
{ }^{2} \text { Chi-squared test } \\
{ }^{3} \text { Fisher's exact test } \\
{ }^{4} \text { Mann-Whitney U-test }\end{array}$ & ; LST-G, laterally spre & or-granular type; LST- & ally spreading tu & nongranula \\
\hline
\end{tabular}

of using TD to perform safe and reliable colorectal ESD, even when performed by a trainee.

Previous reports have indicated that there are differences in anatomical characteristics of the upper gastrointestinal tract and lower gastrointestinal tract, especially the thickness of the muscular layer. Therefore, more caution is necessary when performing colorectal ESD than when performing gastric ESD. Because endoscopic maneuvering greatly varies in the stomach and the colorectum, further experience with colorectal ESD is required even after some degree of experience with gastric ESD has been obtained. It has been reported that 30 to 100 colorectal ESD procedures are required to achieve proficiency, even for experienced gastric ESD endoscopists [26-29]. However, in recent years, there are reports showing that endoscopists without gastric ESD experience can safely perform colorectal ESD [30]. In contrast, this report claimed that more than 100 colorectal ESD procedures are required to achieve proficiency.
Shiga et al. suggested that colonic lesions located at junctions and lesions accompanied with fibrosis should be avoided by novice endoscopists with an experience of fewer than 40 cases of colorectal ESD [31,32]. Other reports have suggested that expert guidance and direct supervision may have contributed to better outcomes [22,23]. However, some reports suggested more stringent requirements such as training protocols, including long periods of observational and supervised ESD procedures as well as animal model training [22, 31, 32].

In the current study, trainees were introduced to colorectal ESD without being limited to the rectum. In fact, there was no significant difference in lesion location in the trainee and expert groups. Further, before attempting human colorectal ESD procedures, trainees did not require training using animal models. The current study found good results of colorectal ESD performed by trainee endoscopists during a short period of 4 months without special selection of lesions. However, there is no doubt that performing ESD in the rectum and learning with 
- Table 2 Comparison of treatment outcomes of the trainee and expert groups.

\begin{tabular}{|c|c|c|c|}
\hline & Trainee $(n=72)$ & Expert $(n=29)$ & $P$ value \\
\hline Completion, n [\%] & $62[86.1]$ & 28 [96.6] & $0.17^{1}$ \\
\hline Traction device was used, $\mathrm{n}$ [\%] & $32[44.4]$ & $6[20.7]$ & $0.03^{2}$ \\
\hline Procedure time, median, minutes & 52.0 & 40.0 & $0.27^{3}$ \\
\hline En bloc resection, $\mathrm{n}[\%]$ & $72[100]$ & $29[96.6]$ & $0.29^{1}$ \\
\hline R0 resection, $\mathrm{n}$ [\%] & $68[94.4]$ & $27[93.1]$ & $1.00^{1}$ \\
\hline Curative resection, n [\%] & $61[84.7]$ & $23[79.3]$ & $0.56^{1}$ \\
\hline \multicolumn{4}{|l|}{ Adverse events, n [\%] } \\
\hline - Perforation & $2[2.8]$ & $0[0.0]$ & $1.00^{1}$ \\
\hline - Postprocedural bleeding & $2[2.8]$ & $0[0.0]$ & $1.00^{1}$ \\
\hline $\begin{array}{l}{ }^{1} \text { Fisher's exact test } \\
{ }^{2} \text { Chi-squared test } \\
{ }^{3} \text { Mann-Whitney U-test }\end{array}$ & & & \\
\hline
\end{tabular}

- Table 3 Baseline characteristics of the 72 lesions treated with ESD by a trainee.

\begin{tabular}{|c|c|c|c|c|}
\hline & With TD $(n=32)$ & Without TD $(n=40)$ & $95 \% \mathrm{Cl}$ & $P$ value \\
\hline Age, mean (SD), years & $68.7(11.1)$ & $64.2(9.6)$ & $-9.38-0.36$ & $0.07^{1}$ \\
\hline Gender, male: female, n [\%] & 14 [44]: $18[56]$ & $19[48]: 21[53]$ & $0.30-2.42$ & $0.75^{2}$ \\
\hline Location, n [\%] & & & $0.06-1.01$ & $0.03^{2}$ \\
\hline Rectum & $4[13]$ & $14[35]$ & & \\
\hline Colon & $28[88]$ & $26[65]$ & & \\
\hline Morphology, n [\%] & & & & $0.61^{3}$ \\
\hline " LST-G & $16[50]$ & $14[35]$ & & \\
\hline - LST-NG & $13[41]$ & $20[50]$ & & \\
\hline - Protruded type & $2[6]$ & $3[8]$ & & \\
\hline . SMT & $1[3]$ & $3[8]$ & & \\
\hline Lesion size, median [interquartile range], mm & $25.0[20.0-30.8]$ & $20.0[17.5-25.5]$ & & $0.12^{4}$ \\
\hline Specimen size, median [interquartile range], mm & $35.0[30.0-42.5]$ & $32.5[27.3-35.0]$ & & $0.12^{4}$ \\
\hline Pathological findings, $\mathrm{n}$ [\%] & & & & $0.10^{3}$ \\
\hline " Adenoma & $21[66]$ & $14[35]$ & & \\
\hline - Intramucosal carcinoma & $7[22]$ & $18[45]$ & & \\
\hline - Slightly invasive $(<1000 \mu \mathrm{m})$ & $1[3]$ & $1[3]$ & & \\
\hline - Deeply invasive ( $\geq 1000 \mu \mathrm{m})$ & $2[6]$ & $4[10]$ & & \\
\hline - Neuroendocrine tumor & $1[3]$ & $3[8]$ & & \\
\hline Residual or recurrent lesion & $4[13]$ & $1[3]$ & $0.50-280.82$ & $0.16^{3}$ \\
\hline Fibrosis, n [\%] & $15[47]$ & $9[23]$ & $0.98-9.59$ & $0.03^{2}$ \\
\hline $\begin{array}{l}\text { ESD, endoscopic submucosal dissection; TD, traction de } \\
\text { tumor-nongranular type; SMT, submucosal tumor. } \\
{ }^{1} \text { Student's t-test } \\
{ }^{2} \text { Chi-squared test } \\
{ }^{3} \text { Fisher's exact test } \\
{ }^{4} \text { Mann-Whitney U-test }\end{array}$ & fidence interval; LST-C & rally spreading tumor - gr & r type; LST-NG, late & spreading \\
\hline
\end{tabular}


- Table 4 Comparison of treatment outcomes with and without TD use by a trainee.

\begin{tabular}{|c|c|c|c|}
\hline & $\begin{array}{l}\text { With TD } \\
(n=32)\end{array}$ & $\begin{array}{l}\text { Without TD } \\
(n=40)\end{array}$ & $P$ value \\
\hline Completion, n [\%] & 26 [81.2] & $36[90.0]$ & $0.32^{1}$ \\
\hline Procedure time, median, minutes & 69.0 & 42.0 & $<0.01^{2}$ \\
\hline En bloc resection, n [\%] & $32[100]$ & $40[100]$ & - \\
\hline R0 resection, n [\%] & 29 [90.6] & $39[97.5]$ & $0.32^{1}$ \\
\hline Curative resection, n [\%] & 28 [87.5] & $33[82.5]$ & $0.74^{1}$ \\
\hline \multicolumn{4}{|l|}{ Adverse events, n [\%] } \\
\hline - Perforation & $1[3.1]$ & $1[2.5]$ & $1.00^{1}$ \\
\hline - Postprocedural bleeding & $1[3.1]$ & $1[2.5]$ & $1.00^{1}$ \\
\hline $\begin{array}{l}\text { TD, traction device } \\
1 \text { Fisher's exact test } \\
{ }^{2} \text { Mann-Whitney U-test }\end{array}$ & & & \\
\hline
\end{tabular}

- Table 5 Trainee experience with endoscopic submucosal dissection.

\begin{tabular}{|l|l|l|l|}
\hline & $\begin{array}{l}\text { Colorectal ESD performed } \\
\text { before the study, } \mathbf{n}\end{array}$ & $\begin{array}{l}\text { Total ESD performed before } \\
\text { the study, } \mathbf{n}\end{array}$ & $\begin{array}{l}\text { Colorectal ESD performed during } \\
\text { the study period, } \mathbf{n}\end{array}$ \\
\hline Endoscopist 1 & 0 & 0 & 10 \\
\hline Endoscopist 2 & 0 & 0 & 11 \\
\hline Endoscopist 3 & 0 & 21 & 21 \\
\hline Endoscopist 4 & 3 & 31 & 13 \\
\hline Endoscopist 5 & 9 & 42 & 17 \\
\hline ESD, endoscopic submucosal dissection & & \\
\hline
\end{tabular}

animal models are still the most effective and essential ways of training. We believe that a major factor that contributed to the good outcomes of ESD performed by trainees in this study was the improved visibility of the submucosal layer provided by the TD. However, further prospective studies are needed to evaluate this.

The S-O clip is one of the first internal TDs that were marketed in Japan in recent years $[19,20]$. This device consists of a spring and a nylon loop that are attached to the endoscopic clip tip. The greatest advantage of this device is that it can be used anywhere without the need to withdraw the endoscope. Furthermore, this device provides offset countertraction independent of the endoscope. In our study, a modified TD without the spring was used. This simple device with a loop made of nylon thread that was attached to the clip is inexpensive and can be easily applied without purchasing any special instruments. The amount of tension can be adjusted simply by the amount of air insufflated in the lumen.

According to the results of the subgroup analyses, unlike in other reports, procedure times were significantly longer in the TD-use group. In contrast, lesions with fibrosis were encountered in a significantly higher proportion of those in the TD-use group. Lesions with fibrosis have been shown to be risk factors for AEs such as perforation and delayed bleeding. It is some- times difficult to perform en bloc resection for these lesions even if the operator is an expert [33]. In addition, the TD was used significantly more in the colon than in the rectum. The colon has a thinner muscle layer and poorer operability than the rectum. As mentioned earlier, a trainee's ESD introduction in the colon is reported to have a high degree of difficulty compared with that in the rectum. On the basis of these results, although longer procedure time is required, even lesions with fibrosis or colonic lesions can be safely treated by a trainee, maintaining a high completion rate with the help of the TD. ESD could not be completed by an expert in one patient with the muscle-retracting sign. This sign is caused by the peristaltic pulling force of the muscular layer beneath the lesion toward the tumor [34]. For this patient, ESD was discontinued and surgery was performed later. For large protruding tumors, risk of severe fibrosis is increased. Although we may be able to safely perform ESD using TD, such lesions should be avoided during introduction of colorectal ESD.

At most medical institutions, even in Japan, only a few trainees are fortunate enough to get the opportunity to perform colorectal ESD. At our institution, we actively promote use of the TD when inexperienced trainees perform colorectal ESD because it improves visibility of the dissection plane, facilitates efficient dissection, and decreases obstacles to ESD. Ohata et al 
reported that direct supervision by experts has contributed to better outcomes [22]. We believe that trainees can perform sufficient ESD using the TD if they are supervised by an expert endoscopist. Furthermore, by incorporating various methods, it may be possible to introduce safer and more efficient ESD procedures that can be performed by trainee endoscopists in the future.

There were several limitations to this study and several biases that might influence study results. First, there may have been a bias in the case selection. The criteria for utilizing the TD are not clear enough. In particular, we did not consider operability, which greatly affects completion of ESD. Maneuverability of the endoscope in the colon is also poor compared with that in the stomach due to presence of semilunar folds, physiological flexion, peristalsis, and respiratory movements. Such technically difficult factors other than lesion location and fibrosis may be taken into consideration in case selection, and it is undeniable that the result of this study may be greatly influenced. Selection bias of patient characteristics and trainees was also an important factor. In addition, there might be information bias of the observer and measurement bias of outcomes in this study. Future well-designed prospective cohort studies that exclude selection bias, or randomized controlled trials, are needed. This study was a retrospective single-facility study. Multicenter studies are necessary to evaluate the generalizability of TD for trainees.

\section{Conclusion}

In conclusion, the usefulness of the TD in colorectal ESD performed by trainee endoscopists was demonstrated in this study. We determined that a trainee endoscopist who performs mentor-guided ESD using the TD can achieve outcomes similar to those of an expert endoscopist. Despite the small sample size, we believe that our findings are convincing; however, further investigations are still warranted.

\section{Acknowledgments}

We thank the medical staff members of the Department of Endoscopy, The Cancer Institute Hospital of Japanese Foundation for Cancer Research for their contribution to this work.

Competing interests

None

\section{References}

[1] Ono $\mathrm{H}$, Kondo $\mathrm{H}$, Gotoda T et al. Endoscopic mucosal resection for treatment of early gastric cancer. Gut 2001; 48: 225-229

[2] Gotoda T, Yamamoto H, Soetikno RM. Endoscopic submucosal dissection of early gastric cancer. J Gastroenterol 2006; 41: 929-942

[3] Chiu PW. Endoscopic submucosal dissection-bigger piece, better outcome! Gastrointest Endosc 2006; 64: 884- 885
[4] Das A. Endoscopic submucosal dissection-cure in one piece. Endoscopy 2006; 38: $1044-1046$

[5] Gotoda T. Endoscopic resection of early gastric cancer. Gastric Cancer 2007; 10: 1-11

[6] Kakushima N, Fujishiro M, Kodashima S et al. Technical feasibility of endoscopic submucosal dissection for gastric neoplasms in the elderly Japanese population. J Gastroenterol Hepatol 2007; 22: 311 314

[7] Oda I, Saito D, Tada M et al. A multicenter retrospective study of endoscopic resection for early gastric cancer. Gastric Cancer 2006; 9 : $262-270$

[8] Saito Y, Uraoka T, Matsuda T et al. A pilot study to assess the safety and efficacy of carbon dioxide insufflation during colorectal endoscopic submucosal dissection with the patient under conscious sedation. Gastrointest Endosc 2007; 65: 537-542

[9] Oka S, Tanaka S, Kaneko I et al. Advantage of endoscopic submucosal dissection compared with EMR for early gastric cancer. Gastrointest Endosc 2006; 64: 877-883

[10] Saito Y, Uraoka T, Yamaguchi Y et al. A prospective, multicenter study of 1111 colorectal endoscopic submucosal dissections (with video). Gastrointest Endosc 2010; 72: 1217-1225

[11] Saito Y, Emura F, Matsuda T et al. A new sinker-assisted endoscopic submucosal dissection for colorectal cancer. Gastrointest Endosc 2005; 62: 297-301

[12] Uraoka T, Kato J, Ishikawa S et al. Thin endoscope-assisted endoscopic submucosal dissection for large colorectal tumors (with videos). Gastrointest Endosc 2007; 66: 836-839

[13] Suzuki S, Gotoda T, Kobayashi Y et al. Usefulness of a traction method using dental floss and a hemoclip for gastric endoscopic submucosal dissection: A propensity score matching analysis (with videos). Gastrointest Endosc 2016; 83: 337-346

[14] Motohashi O. Two-point fixed endoscopic submucosal dissection in rectal tumor (with video). Gastrointest Endosc 2011; 74: 1132 - 1136

[15] Imaeda H, Hosoe N, Ida $\mathrm{Y}$ et al. Novel technique of endoscopic submucosal dissection by using external forceps for early rectal cancer (with videos). Gastrointest Endosc 2012; 75: 1253 - 1257

[16] Oyama T. Counter traction makes endoscopic submucosal dissection easier. Clin Endosc 2012; 45: 375-378

[17] Yamasaki Y, Takeuchi $Y$, Hanaoka $N$ et al. A novel traction method using an endoclip attached to a nylon string during colonic endoscopic submucosal dissection. Endoscopy 2015; 47: (Suppl. 01): E238-239

[18] Yamasaki Y, Takeuchi $\mathrm{Y}$, Uedo $\mathrm{N}$ et al. Traction-assisted colonic endoscopic submucosal dissection using clip and line: A feasibility study. Endosc Int Open 2016; 4: E51 - E55

[19] Sakamoto N, Osada T, Shibuya T et al. Endoscopic submucosal dissection of large colorectal tumors by using a novel spring-action S-O clip for traction (with video). Gastrointest Endosc 2009; 69: 1370 1374

[20] Ritsuno H, Sakamoto N, Osada T et al. Prospective clinical trial of traction device-assisted endoscopic submucosal dissection of large superficial colorectal tumors using the S-O clip. Surg Endosc 2014; 28: $3143-3149$

[21] Ide D, Saito S, Chino A et al. Submucosal pocket creation using a traction device in colorectal endoscopic submucosal dissection. Ann Gastroenterol 2018; 31: 380

[22] Ohata K, Nonaka K, Misumi Y et al. Usefulness of training using anima models for colorectal endoscopic submucosal dissection: is experience performing gastric ESD really needed? Endosc Int Open 2016; 4: E333-E339

[23] Ohya T, Marsk R, Pekkari K. Colorectal ESD in day surgery. Surg Endosc 2017; 31: $3690-3695$ 
[24] Probst A, Golger D, Anthuber M et al. Endoscopic submucosal dissection in large sessile lesions of the rectosigmoid: learning curve in a European center. Endoscopy 2012; 44: 660-667

[25] Yamasaki Y, Takeuchi Y, Uedo $\mathrm{N}$ et al. Efficacy of traction-assisted colorectal endoscopic submucosal dissection using a clip-and-thread technique: A prospective randomized study. Dig Endosc 2018; 30: $467-476$

[26] Hotta K, Oyama T, Shinohara T et al. Learning curve for endoscopic submucosal dissection of large colorectal tumors. Dig Endosc 2010; 22: $302-306$

[27] Niimi K, Fujishiro M, Goto O et al. Safety and efficacy of colorectal endoscopic submucosal dissection by the trainee endoscopists. Dig Endosc 2012; 24: $154-158$

[28] Sakamoto T, Saito Y, Fukunaga $S$ et al. Learning curve associated with colorectal endoscopic submucosal dissection for endoscopists experienced in gastric endoscopic submucosal dissection. Dis Colon Rectum 2011; 54: 1307 - 1312

[29] Jeon HH, Lee HS, Youn YH et al. Learning curve analysis of colorectal endoscopic submucosal dissection (ESD) for laterally spreading tu- mors by endoscopists experienced in gastric ESD. Surg Endosc 2016; 30: $2422-2430$

[30] Yang DH, Jeong GH, Song Y et al. The feasibility of performing colorectal endoscopic submucosal dissection without previous experience in performing gastric endoscopic submucosal dissection. Dig Dis Sci 2015; 60: $3431-3441$

[31] Shiga H, Kuroha M, Endo K et al. Colorectal endoscopic submucosal dissection (ESD) performed by experienced endoscopists with limited experience in gastric ESD. Int J Colorectal Dis 2015; 30: 1645 - 1652

[32] Shiga H, Ohba R, Matsuhashi T et al. Feasibility of colorectal endoscopic submucosal dissection (ESD) carried out by endoscopists with no or little experience in gastric ESD. Dig Endosc 2017; 29: 58 - 65

[33] Lee SP, Kim JH, Sung IK et al. Effect of submucosal fibrosis on endoscopic submucosal dissection of colorectal tumors: pathologic review of 173 cases. J Gastroenterol Hepatol 2015; 30: 872 - 878

[34] Toyonaga T, Tanaka S, Man-I M et al. Clinical significance of the muscle-retracting sign during colorectal endoscopic submucosal dissection. Endosc Int Open 2015; 3: E246-E251 